\title{
Tribological evaluation and lubrication mechanisms of nanoparticles enhanced lubricants in cold rolling
}

\author{
Liang Hao ${ }^{1, *}$, Zheng Wang ${ }^{2}$, Guoyuan Zhang ${ }^{1}$, Yangyang Zhao ${ }^{1}$, Qingjuan Duan ${ }^{1}$, Zhenni Wang ${ }^{2}$, Yongqin Chen ${ }^{1}$, \\ and Tuanjie $\mathrm{Li}^{1}$ \\ ${ }^{1}$ School of Mechano-electronic Engineering, Xidian University, Xi'an 710071, P.R. China \\ 2 School of Advanced Materials and Nanotechnology, Xidian University, Xi'an 710126, P.R. China
}

Received: 23 June 2019 / Accepted: 27 November 2019

\begin{abstract}
Base oils containing different nanoparticles with varying concentrations are prepared, in which $\mathrm{SiO}_{2}$, $\mathrm{TiO}_{2}$ and $\mathrm{ZnO}(20 \mathrm{~nm})$ nanoparticles are employed to improve the lubrication performance. Their tribological properties are evaluated on a ball-on-disk tribometer. The results show that the nano-additive lubricants exhibit a good friction reduction and anti-wear ability at the optimal concentration of $1.0 \mathrm{wt} . \%$, in which $\mathrm{SiO}_{2}$ nanoparticles can reduce the coefficient of friction (COF) and the area of wear scar (AWS) by $45.6 \%$ and $35 \%$, respectively. The $\mathrm{SiO}_{2}$ nanoparticles exhibit the best potential additive tested. The lubrication mechanisms of the nanoparticles can be attributed to the rolling, mending and the protective films.
\end{abstract}

Keywords: Nanoparticles / lubrication mechanisms / cold rolling / ball-on-disk

\section{Introduction}

Applying lubricants during cold rolling can achieve the objectives of industry: dimension accuracy, smooth surface, save energy and reduced roll wear [1]. Over a century, the desirable viscosity and shear strength of oilbased lubricants enable their popularity in the rolling manufacturing industry [2]. However, the interfacial temperature rises easily above $200{ }^{\circ} \mathrm{C}$ in high-speed cold rolling, and high forming pressure together can readily break down the oil films, which severely impair the effectiveness of oil-based lubricants. In addition, it is estimated that the lubrication regime is corresponding to the mixed lubrication [3].

The addition of nanoparticles into lubricants to enhance their performance is not a recent idea. The replacement of organic molecules by nanoparticles has only recently become feasible. Firstly, nanoparticles are not easy to synthesize; and secondly, colloidal solutions are unstable. Nevertheless, these obstacles have been defeated. It has been reported by a number of researchers that the addition of nanoparticles into lubricants exhibits a promising performance in the friction reduction and anti-wear properties, especially in the mixed lubrication regime [4-6]. The applied nanoparticles in the lubricants include metals $[7,8]$, metallic oxides $[9,10]$,

\footnotetext{
* e-mail: haoliang@xidian.edu.cn
}

non-metallic oxides [11], sulfides [12,13], fullerene [14], graphene [15-18] and rare earth compounds [19-21]. The tribological performance of nanoparticles enhancing lubrication depends on the characteristics of nanoparticles, such as types of nanoparticles, size, shape, concentration and work circumstances [22-25]. Well acknowledged lubrication mechanisms for nanoparticles include ball bearing effect, protective film, mending effect and polishing effect [23,26-31]. The ball bearing effect means that particles in nanosize can enter between the mating surfaces and act as ball bearings. The protective film refers to the formation of lubrication films containing nanoparticles. As for the mending effect, the nanoparticles fill the asperities in the rubbing surfaces to reduce the roughness. The polishing effect indicates smoothing the lubricating surfaces abraded by the added nanoparticles.

The nanoparticle chosen to enhance the lubricants in cold rolling must be low cost, non-toxicity, and show good tribological performances in cold rolling similar circumstances. In the present work, three nanoparticle candidates with different concentrations in the base oil will be tested on a ball-on-disk tribometer, including $\mathrm{SiO}_{2}, \mathrm{TiO}_{2}$ and $\mathrm{ZnO}$ with $20 \mathrm{~nm}$ nanoparticles. The objective of this study is to identify the most suitable nanoparticles for the cold rolling lubricants among the three candidates, and reveal the lubrication mechanisms, developing an effective nano-additive lubricant in the practical cold rolling production line. 
Table 1. Chemical compositions of the ball and disk materials (wt.\%)

\begin{tabular}{llllllll}
\hline Materials & $\mathrm{C}$ & $\mathrm{Si}$ & $\mathrm{Mn}$ & $\mathrm{Cr}$ & $\mathrm{Cu}$ & $\mathrm{Mo}$ & $\mathrm{Nb}$ \\
\hline Ball-GCr15 & 1.0 & 0.25 & 0.35 & 1.5 & $\leq 0.25$ & $\leq 0.10$ & - \\
Disk-FSS 444 & 0.0094 & 0.084 & 0.064 & 18.4 & - & 1.81 & 0.22 \\
\hline
\end{tabular}

\section{Experimental}

\subsection{Materials}

GCr15 steel balls and ferritic stainless (FSS) 444 disks were used in this study. The chemical compositions are listed in Table 1. The applied balls with a diameter of $6.0 \mathrm{~mm}$, and the disks were machined to $30 \mathrm{~mm}$ in diameter and $5 \mathrm{~mm}$ in thickness. The Rockwell hardness of the disks was $84 \mathrm{HRC}$, and the surfaces were ground to be uniform with an $R a$ about $0.6 \mu \mathrm{m} . \mathrm{SiO}_{2}, \mathrm{TiO}_{2}$ and $\mathrm{ZnO}$ nanoparticles of approx. $20 \mathrm{~nm}$ in diameter were used, which are commercially supplied by XFNANO Co. Ltd, China.

\subsection{Preparation of nano-additive lubricants}

The detailed preparation of nano-additive lubricants is described as follows: firstly, a constant ratio of degradable palm oil and methyl oleate were mixed and stirred at room temperature to obtain the base oil; secondly, different contents of nanoparticles were added into $50 \mathrm{ml}$ cyclohexane, and then ultrasonically agitated with $50 \mathrm{~min}$ on and 10 min off for at least ten times; thirdly, $50 \mathrm{ml}$ base oil was added into the nano-additive cyclohexane solution, and vigorously stirred using a magnetic stirrer for $30 \mathrm{~min}$. The mixed solution was operated on a rotary evaporator RE2000A by azeotropic distillation, and finally, the nanoparticles were transferred from the cyclohexane solution into the base oil. The different concentrations of nanoparticles being studied in this work include $0.5,1.0,2.0$ and 4.0 wt.\%, which is generally believed to be the effective range of nano-additive lubrication applications. The nanoadditive lubricants were prepared following the flow chart in Figure 1.

\subsection{Tribological tests}

Before applying a new lubricant into the practical cold rolling production line, the lubricant is usually tested on a tribometer. In this article, an CFT-1 multi-functional tribometer was employed to measure the coefficient of friction (COF) values using ball-on-disk tribological tests. Prior to the tests, both balls and disks were cleaned ultrasonically in an ethanol bath for $10 \mathrm{~min}$, and then assembled in the tribometer. The ball-on-disk tests were carried out at room temperature (about $25^{\circ} \mathrm{C}$ ) under different nano-additive lubricants, and each test was repeated at least three times. A constant load of $10 \mathrm{~N}$, equal to $1.4 \mathrm{GPa}$ of the maximum Hertz contact stress, was applied to press the ball against the rotating disk for a period of $30 \mathrm{~min}$. The angular velocity and the diameter of

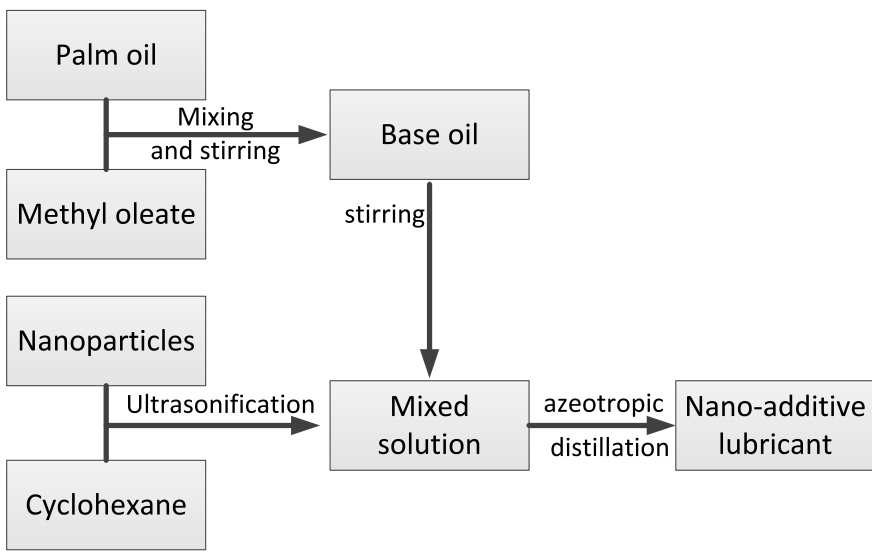

Fig. 1. Flow chart of preparing the nano-additive lubricants.

the wear track were $250 \mathrm{rpm}$ and $7 \mathrm{~mm}$, respectively. During the each test, COF variations were recorded as a function of the sliding time. After testing, the ball and disk were cleaned ultrasonically in ethanol for $10 \mathrm{~min}$ to remove the loose debris and excessive lubricants.

\subsection{Characterization methods}

The morphologies of nanoparticles were examined using a transmission electron microscope (JEM2100). Powder X-ray diffraction (XRD) was implemented on a Bruker D8 Advance diffraction meter with $\mathrm{Cu}-\mathrm{K}_{\alpha}$ radiation. The wear tracks of balls and disks after the tribological tests were observed under a Leica optical microscope and JSM-7800F Scanning Electron Microscope (SEM) equipped with an EDS to evaluate the lubrication mechanisms.

\section{Results and discussion}

\subsection{Materials characterization}

Figure 2 exhibits the original TEM images of the $\mathrm{SiO}_{2}$, $\mathrm{TiO}_{2}$ and $\mathrm{ZnO}$ nanoparticles. It can be seen that the nanoparticles have non-uniform size distribution, and are less spherical, showing irregular morphologies. In addition, nanoparticles are obviously aggregated. The crystalline structures of the applied $\mathrm{SiO}_{2}, \mathrm{TiO}_{2}$ and $\mathrm{ZnO}$ nanoparticles are characterized by XRD diffraction. As shown in Figure $3 \mathrm{a}$, the diffraction peak at $2 \theta=22^{\circ}$ corresponds to the (111) reflection of $\mathrm{SiO}_{2}$ according to PAN-ICSD NO. 01-089-3435. Figure 3b characterizes the diffraction peaks of $\mathrm{TiO}_{2}$, which can be assigned to (101), (004), (200), (105), (211), (213), (220), (215) and (224) planes according to 
PAN-ICSD NO. 01-084-1285. In addition, the diffraction peaks of $\mathrm{ZnO}$ in Figure 3c correspond to (100), (002), (101), (102), (110), (103), (210) and (203) planes according to PAN-ICSD NO. 00-036-1451.

\subsection{Ball-on-disk tests}

The COF statistics of $\mathrm{SiO}_{2}, \mathrm{TiO}_{2}$ and $\mathrm{ZnO}$ nano-additive lubricants with different concentrations is shown in Figure 4. Comparing with the Base oil, $\mathrm{SiO}_{2}$ and $\mathrm{ZnO}$ nanoparticles could reduce the COF at all tested concentrations, while $\mathrm{TiO}_{2}$ nanoparticles aggravate the friction at 2.0 wt. $\%$ and 4.0 wt.\%. The optimal concentrations of these three nanoparticles are $1.0 \mathrm{wt} . \%$, and the $\mathrm{SiO}_{2}$ nanoparticles perform the lowest COF at 0.093 , which is reduced by $45.6 \%$ compared with the base oil. In these tests, friction reduction ability of $\mathrm{ZnO}$ nanoparticles is inferior to $\mathrm{SiO}_{2}$ nanoparticles but superior to $\mathrm{TiO}_{2}$ nanoparticles.

Figure 5 exhibits the optical images of wear scars on balls lubricated with the different concentrations of $\mathrm{SiO}_{2}$ nano-additive lubricants. Grooves can be obviously observed on the wear scars, which are caused by ploughing wear. In addition, the wear scar does not show a circular shape, and the similar phenomenon is found for all wear scars tested. In order to compare the anti-wear ability of the different lubricants, the area of the wear scar (AWS) is adopted, shown in Figure 6. All these three nanoparticles demonstrate a good anti-wear capacity at nearly all concentrations. The $\mathrm{SiO}_{2}$ nanoparticles show the best anti-wear ability at the concentration of $1.0 \mathrm{wt} . \%$, which

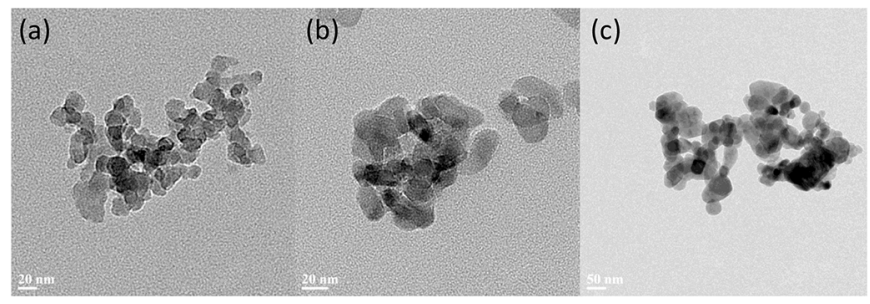

Fig. 2. Original TEM images of $\mathrm{SiO}_{2}$ (a), $\mathrm{TiO}_{2}$ (b) and $\mathrm{ZnO}$ (c) nanoparticles.
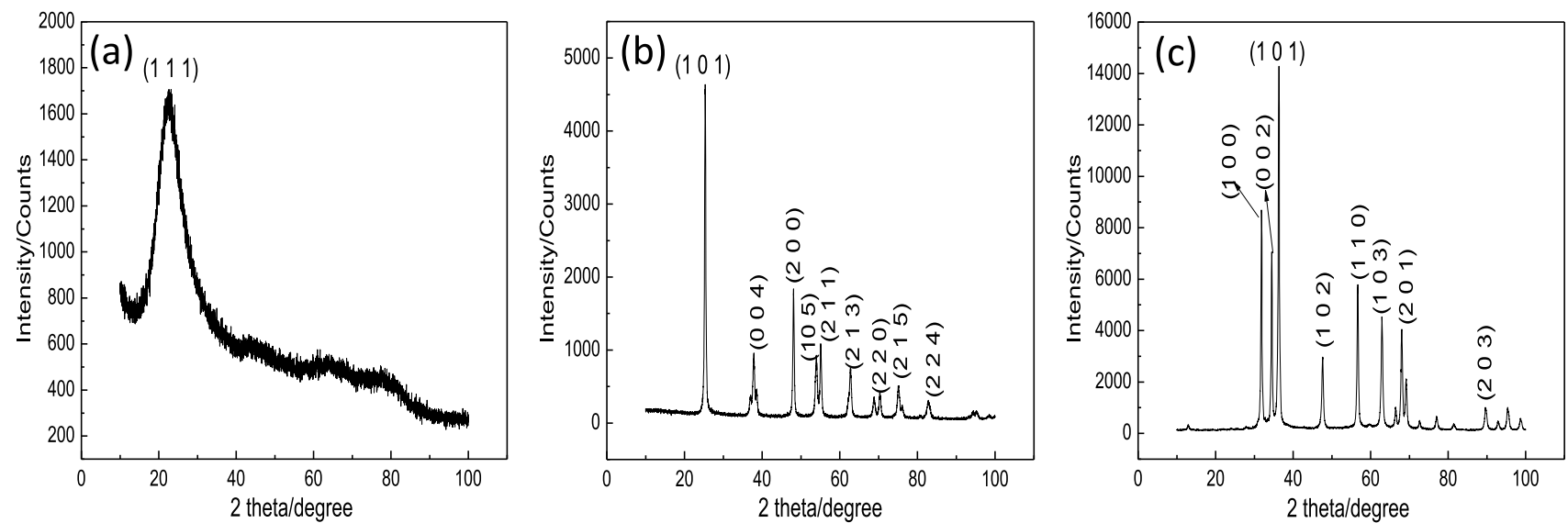

Fig. 3. XRD patterns of $\mathrm{SiO}_{2}(\mathrm{a}), \mathrm{TiO}_{2}$ (b) and $\mathrm{ZnO}$ (c) nanoparticles. reduces the AWS by $35 \%$ compared with the base oil. The $\mathrm{ZnO}$ nanoparticles are a little bit less effective than $\mathrm{SiO}_{2}$ in anti-wear ability but better than $\mathrm{TiO}_{2}$ nanoparticles.

The COF versus time for different nanoparticles at the optimal concentrations (1.0 wt.\%) is presented in Figure 7. The COF for the base oil indicates a rapid increase from the start, and then stabilized at about 0.17 , while the three nano-additive lubricants exhibit a similar trend: a quick increase is observed, and level off for different period. Finally, the COF drops a little and becomes steady. The $\mathrm{SiO}_{2}$ and $\mathrm{TiO}_{2}$ nano-additive lubricants reach peak at 0.11 and 0.165 for a period of $17 \mathrm{~min}$, then reduce to 0.065 and 0.1 until the end, while the $\mathrm{ZnO}$ nano-additive lubricant peaks at 0.125 for a short period $-5 \mathrm{~min}$, then reduces to 0.085 . These three nanoparticles tested have nominal approx. $20 \mathrm{~nm}$ in diameter, and the nano-additive lubricants were prepared in the same manner, so the difference in the lubrication efficiency was attributed to the property variation of the nanoparticles.

\subsection{Surface characteristics of wear tracks}

Figure 8 shows the FE-SEM images of wear tracks lubricated with the base oil and the nano-additive lubricants at the optimal concentration. Numerous irregular islands can be observed in the ploughing grooves, indicating the occurrence of severe adhesive wear [32]. For the base oil (Fig. 8a), a large amount of debris deposited on the trenches, and those debris acted like third-body abrasive. When the nano-additive lubricants were used (Fig. 8b-d), the nanoparticles can be obviously identified in circular shape. Moreover, those irregular islands, consisting of the embedded nanoparticles in the steel substrate debris, fill in the grooves and play the role of friction reduction and anti-wear. Under the other nano-additive concentrations, the less amount of the nanoparticles could deposit on the worn track at the low concentration or the agglomeration at the higher concentrations, resulting in the less efficiency in friction reduction and anti-wear [33,34].

\subsection{Lubrication mechanisms}

Wu et al. [35] investigated the friction and wear characteristics of $\mathrm{TiO}_{2}$ nano-additive water based lubricants on the 


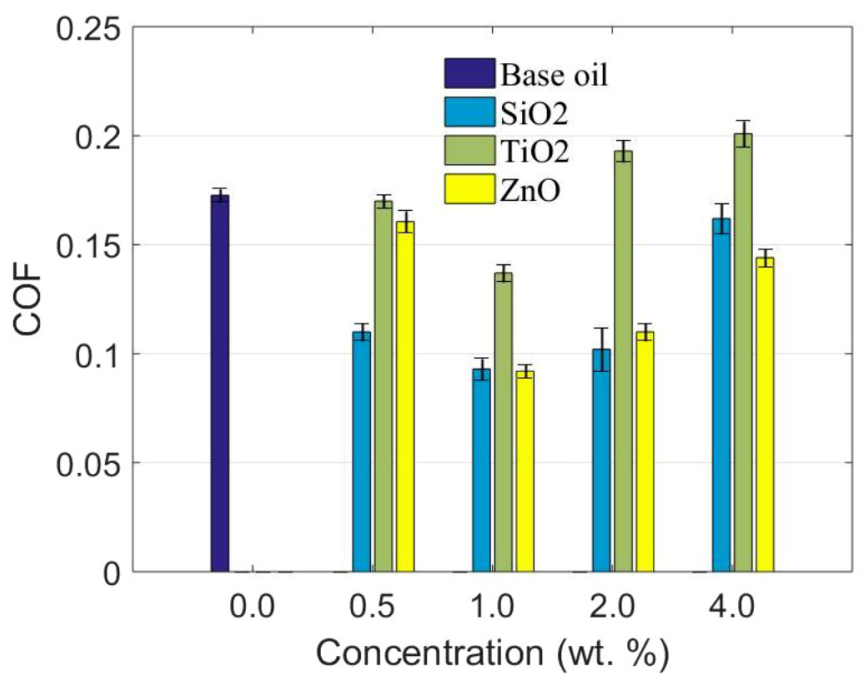

Fig. 4. $\mathrm{COF}$ statistics of $\mathrm{SiO}_{2}, \mathrm{TiO}_{2}$ and $\mathrm{ZnO}$ nano-additive lubricants with different concentrations.

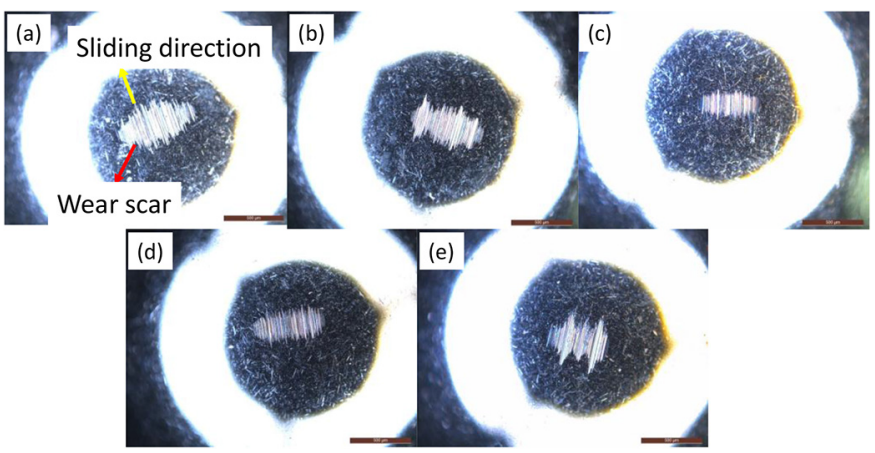

Fig. 5. Optical images of wear scars on balls lubricated with different concentrations of $\mathrm{SiO}_{2}$ nano-additive lubricants, base oil (a), 0.5 wt.\% (b), 1.0 wt.\% (c), 2.0 wt.\% (d) and 4.0 wt.\% (e).

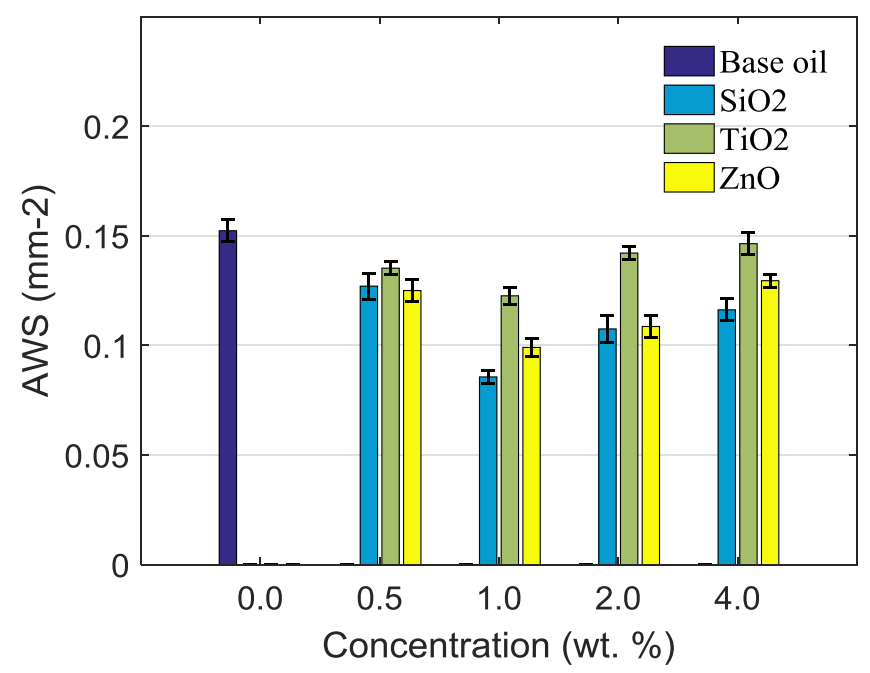

Fig. 6. AWS statistics of $\mathrm{SiO}_{2}, \mathrm{TiO}_{2}$ and $\mathrm{ZnO}$ nano-additive lubricants with different concentrations.

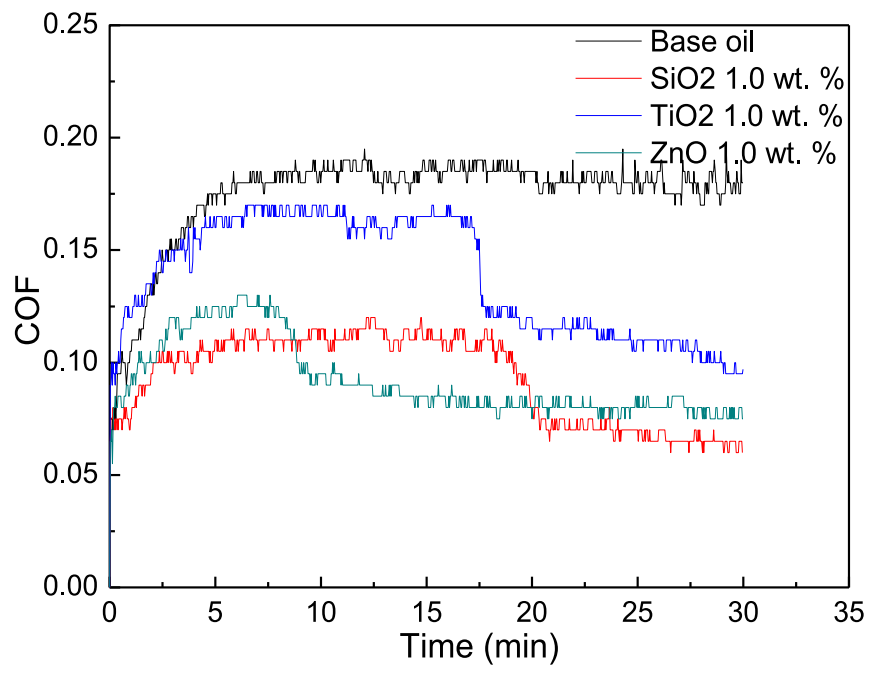

Fig. 7. COF versus time for different nanoparticles at the optimal concentration.

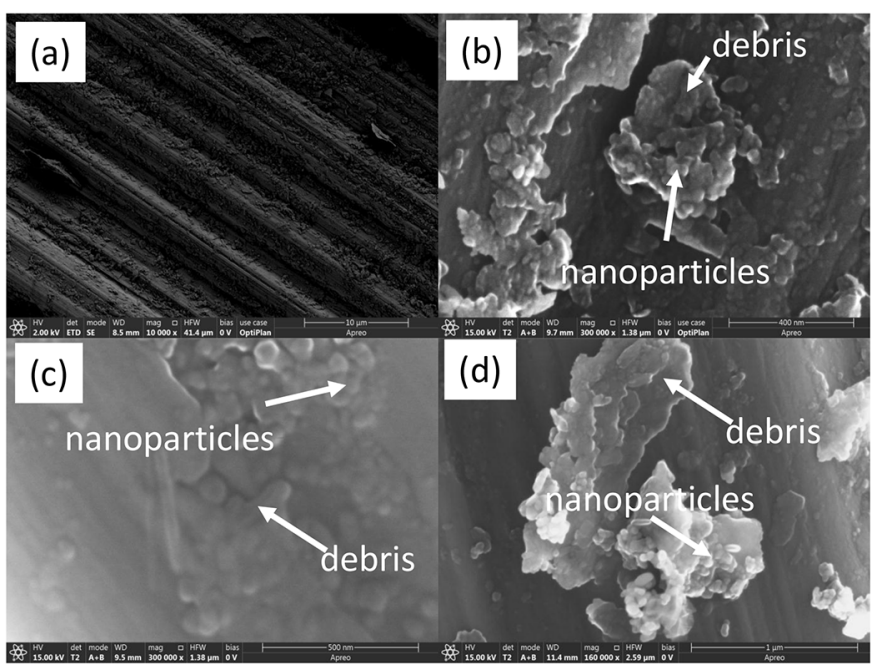

Fig. 8. FE-SEM images of wear tracks lubricated with the base oil (a) and nano-additive lubricants at the optimal concentration (1.0 wt.\%), $\mathrm{SiO}_{2}$ (b), $\mathrm{TiO}_{2}$ (c), $\mathrm{ZnO}(\mathrm{d})$.

FSS 445 disks by the ball-on-clean-disk and ball-on-preoxidised-disk tests at the room temperature. The lubrication mechanisms are primarily ascribed to the formation of tribofilm and the ball-bearing effect of the $\mathrm{TiO}_{2}$ nanoparticles. When the nano- $\mathrm{TiO}_{2}$ lubricant was applied in hot rolling tests of a low-alloy steel, the lubrication mechanisms were owing to the synergistic effect of lubricating film, rolling, polishing, and mending generated by nano- $\mathrm{TiO}_{2}$ [36]. Bao et al. [11] carried out hot rolling experiments under the lubrication of the nano- $\mathrm{SiO}_{2}$ water-based lubricant, and the lubrication performances are related to the functions of micro-rolling, polishing and selfrepairing of the $\mathrm{SiO}_{2}$ nanoparticles. Gara et al. [37] dispersed $\mathrm{ZnO}$ nanoparticles surface functionalized by oleic acid into paraffinic mineral oil, and conducted tribological 


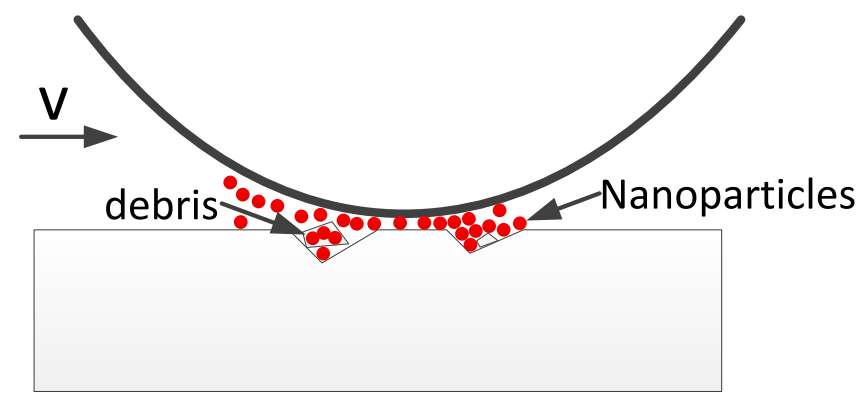

Fig. 9. Schematic diagram of the lubrication mechanisms of the nanoparticles.

tests on a ball-o-disk configuration. The contribution of the $\mathrm{ZnO}$ nanoparticles to friction reduction might be because these particles acted as nanosize bearings rather than their deposition on the surface.

There is no one nanoparticles which can effectively reduce friction and perform anti-wear under all circumstances, and the lubrication mechanisms vary from case to case. In the light of the analysis above, the lubrication mechanisms of these three nano-additive lubricants and their efficiency under the test circumstances can be summarized. In terms of the ball-on-disk tests, the circular nanoparticles are clearly distinguished (Fig. 8bd), the "rolling effect" of nanoparticles is deduced. Prior to the SEM observations, the disks after the wear tests were ultrasonically cleaned, and may remove part of the nanoparticles. In addition, a large number of nanoparticles fill in the trenches among the disks. During the wear tests, these nanoparticles embedded into the substrate debris and existed in the rubbing surface, preventing the ball from direct contact with the disk. The nanoparticles re-entered the mating surfaces, and the replenishment and consumption of the nanoparticles between the surfaces could reach a dynamic balance as the tests proceeding. The dynamic flow also took away the debris between the ball and disk, and the nanoparticles entering the rubbing surfaces could fill up the microgrooves and smooth the surface, which is called "mending" effect. Tribo-sintering also occurred, and the nanoparticles were compressed into the irregular islands, which is called the protective films [38]. Overall, $\mathrm{SiO}_{2}$ nanoparticles perform the best in friction reduction and anti-wear according to the COF and AWS (Figs. 4 and 6) curves. The friction reduction and anti-wear mechanisms of the nano-additive lubricants are shown in Figure 9.

\section{Conclusions}

In this study, different concentrations of $\mathrm{SiO}_{2}, \mathrm{TiO}_{2}$ and $\mathrm{ZnO}$ nano-additive lubricants were successfully prepared through repeated ultrasonification and azeotropic distillation. Tribological properties of these nano-additive lubricants were tested on a ball-on-disk tribometer. The lubrication mechanisms were analysed by FE-SEM analysis. The conclusions drawn from this study are shown as follows:

- The nanoparticles have been successfully transferred into the base oil through ultrasonification and azeotropic distillation.

- These three nano-additve lubricants exhibit a good friction reduction and anti-wear at the concentration of 1.0 wt.\%. The $\mathrm{SiO}_{2}$ nanoparticles show the best potential additive under the tested circumstances, which can reduce COF by $45.6 \%$ and ASW by $35 \%$.

- The rolling, mending and the protective films are considered as the lubrication mechanisms of the tested nano-additive lubricants.

The authors are grateful for the financial support from the National Natural Science Foundation of China (51904217); the Fundamental Research Funds for the Cenral Universities (No. JBX170409 and No. XJS17003).

\section{References}

[1] L. Barbulovic-Nad, J.G. Lenard, The effect of tallow concentration on the cold rolling of steel strips, J. Mater. Process. Technol. 142, 65-71 (2003)

[2] A. He, S. Huang, J.-H. Yun, H. Wu, Z. Jiang, J. Stokes, S. Jiao, L. Wang, H. Huang, Tribological performance and lubrication mechanism of alumina nanoparticle water-based suspensions in ball-on-three-plate testing, Tribol. Lett. 65, 40-50 (2017)

[3] A. Azushima, Tribology in Sheet Rolling Technology, Springer International Publishing, 2016

[4] S.P. Darminesh, N.A.C. Sidik, G. Najafi, R. Mamat, T.L. Ken, Y. Asako, Recent development on biodegradable nanolubricant: A review, Int. Commun. Heat Mass Transfer 86, 159-165 (2017)

[5] S.A. Angayarkanni, J. Philip, Review on thermal properties of nanofluids: recent developments, Adv. Colloid Interface Sci. 225, 146-176 (2015)

[6] K.S. Suganthi, K.S. Rajan, Metal oxide nanofluids: review of formulation, thermo-physical properties, mechanisms, and heat transfer performance, Renew. Sustain. Energy Rev. 76, $226-255$ (2017)

[7] F.L. Guzman Borda, S.J. Ribeiro de Oliveira, L.M. Seabra Monteiro Lazaro, A.J. Kalab Leiróz, Experimental investigation of the tribological behavior of lubricants with additive containing copper nanoparticles, Tribol. Int. 117, 52-58 (2018)

[8] D. Li, B. Hong, W. Fang, Y. Guo, R. Lin, Preparation of welldispersed silver nanoparticles for oil-based nanofluids, Ind. Eng. Chem. Res. 49, 1697-1702 (2010)

[9] A. Bahramian, K. Raeissi, A. Hakimizad, An investigation of the characteristics of $\mathrm{Al}_{2} \mathrm{O}_{3} / \mathrm{TiO}_{2}$ PEO nanocomposite coating, Appl. Surf. Sci. 351, 13-26 (2015)

[10] T. Luo, X. Wei, X. Huang, L. Huang, F. Yang, Tribological properties of $\mathrm{Al}_{2} \mathrm{O}_{3}$ nanoparticles as lubricating oil additives, Ceram. Int. 40, 7143-7149 (2014)

[11] Y. Bao, J. Sun, L. Kong, Effects of nano-SiO $\mathrm{S}_{2}$ as water-based lubricant additive on surface qualities of strips after hot rolling, Tribol. Int. 114, 257-263 (2017) 
[12] P.U. Aldana, B. Vacher, T. Le Mogne, M. Belin, B. Thiebaut, F. Dassenoy, Action mechanism of WS2 nanoparticles with ZDDP additive in boundary lubrication regime, Tribol. Lett. 56, 249-258 (2014)

[13] H. Wu, B. Johnson, L. Wang, G. Dong, S. Yang, J. Zhang, High-efficiency preparation of oil-dispersible $\mathrm{MoS}_{2}$ nanosheets with superior anti-wear property in ultralow concentration, J. Nanoparticle Res. 19, 339-349 (2017)

[14] B.-C. Ku, Y.-C. Han, J.-E. Lee, J.-K. Lee, S.-H. Park, Y.-J. Hwang, Tribological effects of fullerene (C60) nanoparticles added in mineral lubricants according to its viscosity, Int. J. Precis. Eng. Manufactur. 11, 607-611 (2010)

[15] A.K. Rasheed, M. Khalid, W. Rashmi, T.C.S.M. Gupta, A. Chan, Graphene based nanofluids and nanolubricants Review of recent developments, Renew. Sustain. Energy Rev. 63, 346-362 (2016)

[16] A. He, S. Huang, J.-H. Yun, Z. Jiang, J. Stokes, S. Jiao, L. Wang, H. Huang, The pH-dependent structural and tribological behaviour of aqueous graphene oxide suspensions, Tribol. Int. 116, 460-469 (2017)

[17] O. Elomaa, V.K. Singh, A. Iyer, T.J. Hakala, J. Koskinen, Graphene oxide in water lubrication on diamond-like carbon vs. stainless steel high-load contacts, Diamond Related Mater. 52, 43-48 (2015)

[18] H.-J. Song, N. Li, Frictional behavior of oxide graphene nanosheets as water-base lubricant additive, Appl. Phys. A 105, 827-832 (2011)

[19] C. Zhao, A study of tribological properties of water-based ceria nanofluids, Tribol. Lubricat. Technol. 73, 56-65 (2012)

[20] K. Gu, B. Chen, Y. Chen, Preparation and tribological properties of lanthanum-doped $\mathrm{TiO}_{2}$ nanoparticles in rapeseed oil, J. Rare Earths 31, 589-594 (2013)

[21] C. Boshui, G. Kecheng, F. Jianhua, W. Jiang, W. Jiu, Z. Nan, Tribological characteristics of monodispersed cerium borate nanospheres in biodegradable rapeseed oil lubricant, Appl. Surf. Sci. 353, 326-332 (2015)

[22] R.A. Andrievski, A.V. Khatchoyan, Nanomaterials in extreme environments: fundamentals and applications, MRS Bull. (2016)

[23] S. Shahnazar, S. Bagheri, S.B. Abd Hamid, Enhancing lubricant properties by nanoparticle additives, Int. J. Hydrogen Energy 41, 3153-3170 (2016)

[24] D. Maharaj, B. Bhushan, Friction, wear and mechanical behavior of nano-objects on the nanoscale, Mater. Sci. Eng. R 95, 1-43 (2016)

[25] G. Dan, X. Guoxin, L. Jianbin, Mechanical properties of nanoparticles: basics and applications, J. Phys. D: Appl. Phys. 47, 1-25 (2014)
[26] W. Dai, B. Kheireddin, H. Gao, H. Liang, Roles of nanoparticles in oil lubrication, Tribol. Int. 102, 88-98 (2016)

[27] M. Bahiraei, Particle migration in nanofluids: a critical review, Int. J. Therm. Sci. 109, 90-113 (2016)

[28] T. Sui, B. Song, F. Zhang, Q. Yang, Effects of functional groups on the tribological properties of hairy silica nanoparticles as an additive to polyalphaolefin, RSC Adv. 6, 393-402 (2016)

[29] T. Sui, B. Song, F. Zhang, Q. Yang, Effect of particle size and ligand on the tribological properties of amino functionalized hairy silica nanoparticles as an additive to polyalphaolefin, J. Nanomater. 2015, 1-9 (2015)

[30] J.A. Ranga Babu, K.K. Kumar, S. Srinivasa Rao, State-ofart review on hybrid nanofluids, Renew. Sustain. Energy Rev. 77, 551-565 (2017)

[31] W. Xia, J. Zhao, H. Wu, S. Jiao, X. Zhao, X. Zhang, J. Xu, Z. Jiang, Analysis of oil-in-water based nanolubricants with varying mass fractions of oil and $\mathrm{TiO}_{2}$ nanoparticles, Wear 396-397, 162-171 (2018)

[32] E. Gnecco, E. Meyer, Fundamentals of Friction and Wear on the Nanoscale, Springer International Publishing, 2015

[33] H. Wu, J. Zhao, W. Xia, X. Cheng, A. He, J.H. Yun, L. Wang, H. Huang, S. Jiao, L. Huang, S. Zhang, Z. Jiang, A study of the tribological behaviour of $\mathrm{TiO}_{2}$ nano-additive water-based lubricants, Tribol. Int. 109, 398-408 (2017)

[34] X. Yan, J. Sun, S. Xiong, Effects of lubricants on the rolling performances of cold rolled copper strips, Proc. Eng. 207, 2227-2232 (2017)

[35] H. Wu, J. Zhao, X. Cheng, W. Xia, A. He, J.-H. Yun, S. Huang, L. Wang, H. Huang, S. Jiao, Z. Jiang, Friction and wear characteristics of $\mathrm{TiO} 2$ nano-additive water-based lubricant on ferritic stainless steel, Tribol. Int. 117, 24-38 (2018)

[36] H. Wu, J. Zhao, L. Luo, S. Huang, L. Wang, S. Zhang, S. Jiao, H. Huang, Z. Jiang, Performance evaluation and lubrication mechanism of water-based nanolubricants containing nano- $\mathrm{TiO}_{2}$ in hot steel rolling, Lubricants 6, 57-71 (2018)

[37] L. Gara, Q. Zou, Friction and wear characteristics of oilbased $\mathrm{ZnO}$ nanofluids, Tribol. Trans. 56, 236-244 (2013)

[38] G. Liu, X. Li, B. Qin, D. Xing, Y. Guo, R. Fan, Investigation of the mending effect and mechanism of copper nanoparticles on a tribologically stressed surface, Tribol. Lett. 17, 961-966 (2004)

Cite this article as: L. Hao, Z. Wang, G. Zhang, Y. Zhao, Q. Duan, Z. Wang, Y. Chen, T. Li, Tribological evaluation and lubrication mechanisms of nanoparticles enhanced lubricants in cold rolling, Mechanics \& Industry 21, 108 (2020) 